\title{
Sulfur reduction in Sangan iron ore by flotation
}

\author{
Bahram Rezaee ${ }^{l}$, Atefe Sarvi ${ }^{*}, 2$, Atiyeh Eslamian², Seyed MehdiJebraeeli ${ }^{2}$, and Abolfazl Zabihi ${ }^{3}$ \\ ${ }^{1}$ Mineral Processing, professor, mining and metallurgical engineering department, Amirkabir university of technology, Tehran, Iran. \\ ${ }^{2}$ Mineral Processing, Expert of Mineral Processing Department of KaniKavan shargh Engineering Co., Tehran, Iran. \\ ${ }^{3} \mathrm{Head}$ of technology and development of Opal Parsian Sangan industrial \& Mining Co.(OPSIM), Tehran, Iran.
}

\begin{abstract}
Sangan iron ore in Iran, was investigated. For this purpose the effect of collector type, $\mathrm{pH}$, collector concentration and stage dosing on reverse flotation of iron sulfide ore from magnetite ore was investigated. Two type of thiol collectors include xanthates (sodium isopropyl xanthate (SIPX) and potassium amyl xanthate (PAX)) and dithiocarbamate (di-ethyl dithiocarbamate (DTC)) and the mixture of collectors was studied. The highest sulfur removal was obtained with potassium amyl xanthate. Stage dosing had a significant effect in sulfide flotation and the best recovery was obtained when the collector was added in 4 stages. The acidity had a positive effect on sulfide floatability and the best result was obtained at $\mathrm{pH}$ 3.5-4. Investigation about collector concentration showed that increasing the SIPX concentration enhanced the sulfur removal but this factor was not effective for PAX.
\end{abstract}

\section{Introduction}

The Sangan Iron Ore Deposit forms part of the east-west trending Kuh-e-Taleb mountain range, and is located at Sangan at latitude $\mathrm{N} 34^{\circ} 24^{\prime}$, longitude E $60^{\circ} 16^{\prime}$ in the Khorasan Province, North-Eastern Iran. This deposit involves several anomalies with different specification.

This study investigate anomaly C-north which is identified as high sulfur magnetite ore. The grade of sulfur in this anomaly varied from 1 to 8 percent which is higher than the norm of iron ore. Pyrite is the main source of sulfur in this ore which is accompanied with less amount pyrrhotite. So in order to reduce the sulfur content, reverse flotation was designed in concentration plant.

Thiol collectors are commonly used in the froth flotation of sulfide minerals. The xanthates, dithiophosphates and dithiocarbamates are classes of thiol collectors that each form different surface products on different sulfide minerals [1].

Xanthates have been the collector of choice for the flotation of sulfide minerals ever since the flotation process was developed and have been studied quite extensively [2]. Also it has been shown that the use of mixtures of thiol collectors can have benefits over the use of pure collectors $[1,3]$.

It has been observed, that an increase in xanthate concentration increased the grade of the concentrates in pyrite flotation, this is attributed to the fact that this factors increase the hydrophobicity of the pyrite and thus enhance elutriation in the froth phase [4]. Also the investigations have been shown the quality of the concentrate floated improves if collector is stage-added. Stage-adding collector involves dividing the total collector and adding it in several stages instead of one[5].The other factor which has been studied widely on sulfide flotation is the effect of $\mathrm{pH}$. The previous studies say the best pyrite recovery is obtained at acidic condition but there is evidence that an acceptable pyrite recovery in alkaline condition is avoidable too [6].

In this study it has been tried to improve the quality of iron concentrate by improving the flotation of sulfur impurity. For this purpose the effect of collector type, $\mathrm{pH}$, collector concentration and stage dosing on reverse flotation of iron sulfide from magnetite ore was investigated. Two type of thiol collectors include xanthates (sodium isopropyl xanthate (SIPX) and potassium amyl xanthate (PAX)) and dithiocarbamate (di-ethyl dithiocarbamate (DTC)) and the mixture of collectors were studied.

\section{Material and method}

\subsection{Method}

Considering the presence of iron sulfide (mainly pyrite) as impurity in magnetite concentrate, the reverse flotation was designed for removal of these sulfides.

Flotation experiment was carried out in a lab scale Denver flotation cell which was self air injecting for bubble generation. The sample in each test was $1 \mathrm{~kg}$ magnetite with $\mathrm{d} 80<38 \mu \mathrm{m}$. Analytical grade sodium isopropyl xanthate (SIPX), potassium amyl xanthate (PAX) and di-ethyl dithiocarbamate (DTC) were used as collector in different tests and MIBC was used as frother in all tests. The $\mathrm{pH}$ was adjusted by addition $\mathrm{HCl}$ and

\footnotetext{
*Corresponding author: at.sarvi@gmail.com
} 
$\mathrm{NaOH}$ and measured by $\mathrm{pH}$ meter. The tests were carried out by $30 \%$ weight solid content. The floated and unfloated samples were collected separately, dried and weighted and then were sent for iron and sulfide analysis. Titration was used for iron and LECO for sulfur analysis.

\subsection{Material}

The samples used in this experiment were taken from Sangan concentrate plant. This plant uses low intensive magnetic separator (LIMS) for concentration of anomaly $\mathrm{C}$-north from Sangan iron ore. The samples were taken from the final concentrate of LIMS, so the liberated part of iron sulfide was removed in magnetic separation. Experiment was designed to removes that part of iron sulfide which is engaged with magnetite and cannot be separated by magnetic separators. Chemical analysis of sample was given in table 1 . Chemical analysis was done with Atomic Absorption Spectrometry.

According to the results the grade of sulfur exceeds the norm of sulfur in iron concentrate so it can be considered as the main impurity of the samples.

The mineralogical studies were done for identifying the type of minerals and their engagement. The result showed that magnetite is the main phase but in some places it oxidized to hematite Fig. 1.

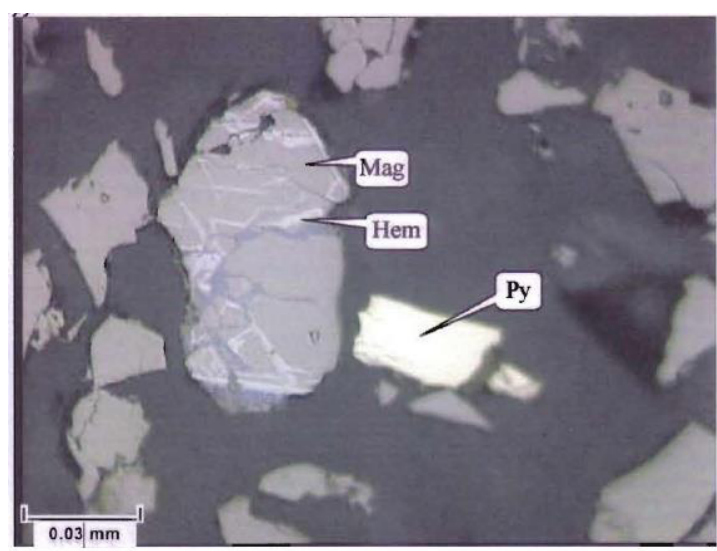

Fig. 1. Magnetite (Mag) is oxidized to hematite (Hem) with liberated pyrite (Py).
Sulfide was observed in two phase pyrite and pyrrhotite but domination is with pyrite. These minerals have different type of engagement with magnetite. In Fig. 1,2 pyrite and pyrrhotite are completely liberated while in Fig 3 pyrite has an intensive engagement with magnetite and this is the part that usually are not separated with magnetite separator.

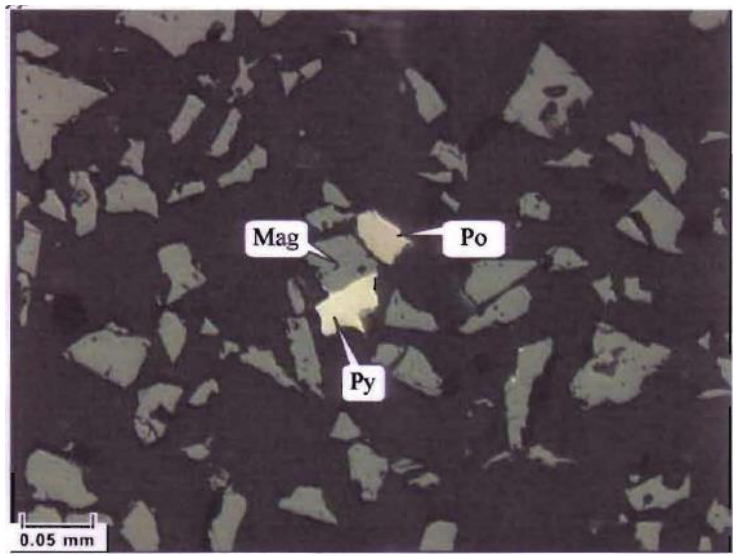

Fig. 2. Pyrite (Py) in contact with magnetite (Mag) and liberated pyrrhotite $(\mathrm{Po})$.

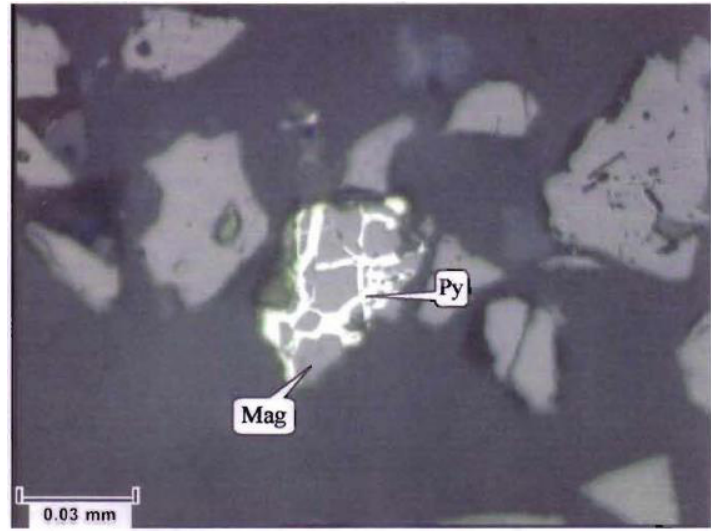

Fig. 3. Pyrite (py) and magnetite (Mag) engagement.

Table 1. Chemical analysis of sample.

\begin{tabular}{|c|c|c|c|c|c|c|c|c|c|c|c|c|}
\hline $\begin{array}{r}\text { Element } \\
\text { Sample }\end{array}$ & $\mathbf{F e}$ & $\mathbf{S i O}_{2}$ & $\mathbf{A l 2 O}_{3}$ & $\mathbf{C a O}$ & $\mathbf{M g O}$ & $\mathbf{P}$ & $\mathbf{S}$ & $\mathbf{N a} 2 \mathbf{O}$ & $\mathbf{K}_{2} \mathbf{O}$ & $\mathbf{M n}$ & $\mathbf{T i O}_{2}$ & $\mathbf{V}$ \\
\hline $\mathbf{A}$ & 66.07 & 1.65 & 0.6 & 0.125 & 3.84 & $<0.01$ & 0.85 & 0.01 & 0.014 & 0.205 & 0.07 & 0.004 \\
\hline $\mathbf{B}$ & 66.4 & 1.43 & 0.75 & 0.19 & 4.35 & $<0.01$ & 0.72 & 0.01 & 0.01 & 0.125 & 0.06 & 0.004 \\
\hline $\mathbf{C}$ & 67.4 & 0.93 & 0.6 & 0.06 & 3.9 & $<0.01$ & 0.45 & 0.005 & 0.007 & 0.145 & 0.06 & 0.004 \\
\hline
\end{tabular}

\section{Result}

In this study the flotation of iron sulfide minerals especially pyrite as the main sulfide impurity of Sangan magnetite ore was investigated. For this purpose, Three different collectors include sodium isopropyl xanthate (SIPX), potassium amyl xanthate (PAX) and diethyl dithiocarbamate (DTC) which all of them are known as thiol collectors, were tested. The result was depicted on Fig 4.

According to the result, xanthates are better collectors for iron sulfide minerals compare to dithiocarbamate and between the two tested xanthate, PAX showed the best sulfide removal. It is supposed, because of longer carbon chain, PAX is stronger collector and more effective in iron sulfide flotation. [7, 8]. 


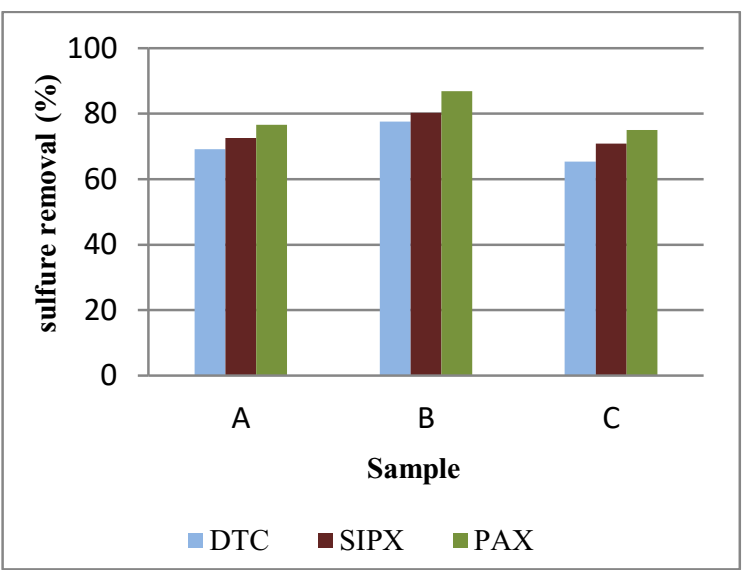

Fig. 4. The effect of collector type on removal of iron sulfide ore from magnetite ore by flotation.

It has been shown that in some cases the use of mixtures of thiol collectors has benefits over the use of pure collectors, so mixture of PAX-DTC was investigated [2]. In this order DTC and PAX (SIPX) was added respectively with some interval with this logic that when a mixture of collectors is exposed sequentially to a surface which by definition must have a heterogeneous distribution of energetically different sites, the weaker collector (DTC) will adsorb preferentially on the strong sites and the strongly adsorbing collector (PAX), added subsequently, will adsorb on the weaker sites. In this way as many sites as possible are utilized for adsorption thus enhancing the hydrophobicity [9]. The result is shown in Fig5.

According to the results, the mixture of PAX-DTC is not effective and could not enhance the floatability of iron sulfide ore and even deteriorate the effect of pure PAX. So this parameter was overruled.

The experiments showed that the sulfur removal is improved if collector is stage -added [5]. Stage adding involves adding collector in several stages. According to Fig 6, the best recovery was obtained when collector is added in four stages. It seems with this strategy the collector concentration almost remain constant during the flotation. The main part of collector is consumed at first stage of flotation and consequently the collector concentration reduced in cell, with stage dosing, collector concentration remains almost constant during the flotation.

The effect of acidity is the other parameter which was investigated. In Fig. 7, the sulfur removal percentage in different $\mathrm{pH}$ was shown. PAX and SIPX showed almost the same behavior. The floatability was low at high acidic $\mathrm{pH}$, probably due to the decomposition of the collector and typically reaches its maximum at around $\mathrm{pH} 3.5-4$. As the $\mathrm{pH}$ was increased, an intermediate depression in the iron sulfide recovery was observed. It seems that the formation of the hydrophilic ferric hydroxide which is the stable iron species in an alkaline medium is responsible for this phenomenon. Pyrite recovery increases gradually after $\mathrm{pH} 5$ and show a second peak at $\mathrm{pH}$ around 9 and then it drops dramatically as $\mathrm{pH}$ increases. According to Göktepe (2002) at pH 5, pyrite is very soluble and iron ions released from the surface of pyrite are found to have an important effect on collector adsorption where these ions can cause rapid oxidation of xanthate to dixanthogen[10]. The decrease in recovery above $\mathrm{pH}$, 9 was due to the formation of $\mathrm{Fe}(\mathrm{OH})_{2}$ on pyrite.

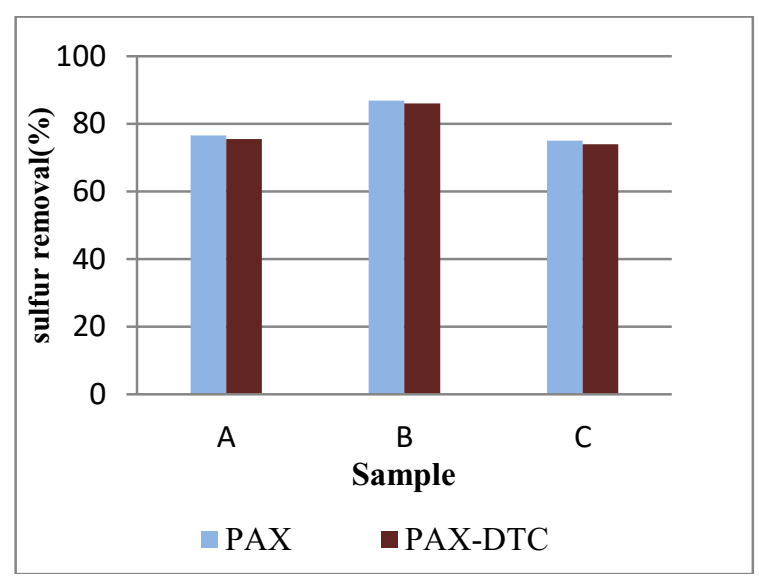

Fig. 5. The effect of collector mixture on iron sulfide flotation

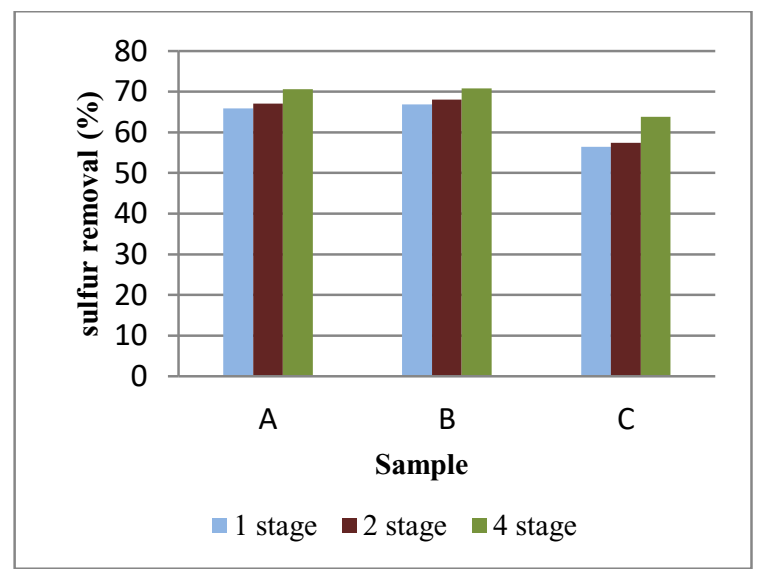

Fig. 6. The effect of stage adding of collector on flotation of iron sulfide minerals.

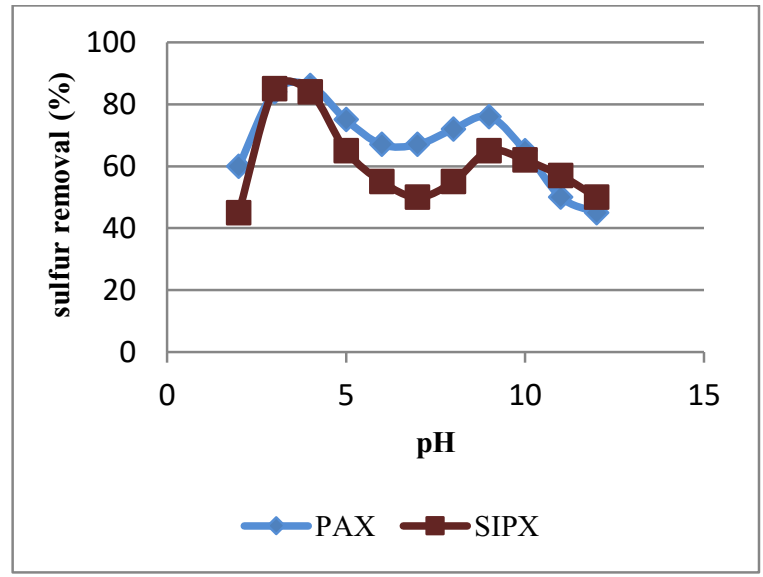

Fig. 7. The effect of $\mathrm{pH}$ on iron sulfide flotation. 


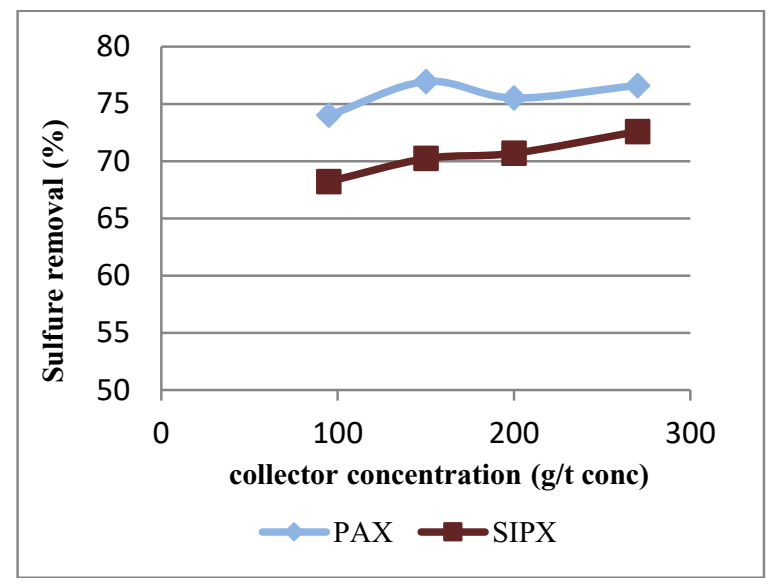

Fig. 8. The effect of collector concentration on flotation of iron sulfide minerals.

The floatability of iron sulfide minerals with variable collector concentration showed that increasing the SIPX concentration improved the sulfur removal but the PAX concentration almost did not affect the sulfide removal in the range of this investigation. The results are depicted in fig. 8 .

\section{Conclusion}

In this study the flotation of iron sulfide minerals especially pyrite as the main sulfide impurity of Sangan magnetite ore was investigated. For this purpose the effect of collector type, $\mathrm{pH}$, collector concentration and stage dosing was studied. The result showed that xanthate is better collector for iron sulfide minerals compare to dithiocarbamate and between the two tested xanthates, PAX showed the best sulfide removal. The mixture of PAX as the strong and dithiocarbamate as the weak collector was ineffective in iron sulfide flotation as it was expected and even it deteriorate the effect of pure PAX.The experiments showed that the sulfur removal is improved if collector added in 4 stage during the flotation instead of one stage at the beginning.
Acidity has different effect on floatability of iron sulfide, the recovery is improved at acidic condition around $\mathrm{pH} 3.5-4$, but there is a second peak in recovery at alkali condition at $\mathrm{pH} 9$ albeit the second recovery is pretty weaker than the first one.

The floatability of iron sulfide minerals with variable collector concentration showed that increasing the SIPX concentration improve the sulfur removal but the PAX concentration almost did not affect the sulfide removal in the range of this investigation.

The authors would gratefully acknowledge Opal Parsian Sangan Industrial \& Mining Co. (OPSIM), in providing them with funding and opportunity to complete this work. The authors would like to express their deepest gratitude to Mr. Kambiz Moazami Managing Director of Kanikavan Shargh Engineering Co. and colleagues in the company, for their support.

\section{References}

1. G. Hangone, D. Bradshaw and Z. Ekmekci, J. South. Afr. Inst. Min. Metall., 105, 199-206 (2005)

2. R. Plessis, J.D. Miller,XXII International Mineral Processing Congress, 892-901 (2003)

3. D.J Bradshaw, C.TO'Connor, J. South. Afr. Inst. Min. Metall., 89-96 (1996)

4. A.Dimou, thesis for master degree (University of Cape Town, 1986)

5. https://www.911metallurgist.com/blog/stage addition of flotation-reagents

6. R Mermillod-Blondin, Centenary of Flotation Symposium, 683-692 (2005)

7. B Rezai, Flotation, 52-54 (1996)

8. B A. Wills, T Napier-Munn, Mineral Processing Technology, 270-273 (2006)

9. D.J. Bradshaw, P.J. Harris and C.T. O’Connor, J. South. Afr. Inst. Min. Metall.,189-194 (1998)

10. F Göktepe, Turkish J. Eng. Env. Sci, 26, 309-318 (2002) 